\title{
NIH plans for chimps
}

To the editor-In the July issue of Nature Medicine, Kris Novak reported on a conflict between townspeople of Carignan, Quebec, and a chimp sanctuary located there, and also speculated that "public outrage at local housing of HIV-infected chimps may become more common, as primate centers will eventually need to find retirement homes...." Novak concluded by stating that the National Institutes of Health (NIH) had been urged by the National Academy of Science to establish a chimpanzee management program, but had not done so thus far. To the contrary, the NIH quickly responded to the study recommendations of the National Research Council (NRC) - a research arm of the National Academy of Science-and in September 1998, established the national Chimpanzee Management Program (ChiMP). In fact, it was the NIH that initiated the NRC study when it sought the council's advice on research and retirement challenges posed by HIV-infected research chimpanzees.

The National Center for Research Resources at the NIH crafted the management program based on NRC guidance. The NCRR is now considering the concerns of disparate individuals and organizations with an interest in research chimpanzees, including research scientists, chimpanzee colony managers, individuals concerned about chimpanzee welfare, members of the public and others.

The physical capacity of existing facilities and additional infrastructure needs are being assessed; restrictions on breeding of these chimpanzees have been imposed; and policies for ownership transfer of non-NIH-owned chimpanzees are being established. The ChiMP will ensure that each chimpanzee is screened for potential public health risks and that complete medical and research histories on each animal are stored in a central database. Finally, these chimpanzees will be categorized and grouped in optimal colony sizes at ChiMP-approved facilities.

The biomedical research community and society now have no easy solutions to the challenges associated with the use of chimpanzees in research. But the NIH has taken a leadership role and an important step forward to maximize a valuable research resource. An outline of the ChiMP may be viewed at http://www.ncrr.nih.gov/compmed.htm.

JOHN STRANDBERG

Director, Comparative Medicine

National Center for Research Resources

National Institutes of Health

Bethesda, Maryland 20892-7965, USA

\section{AIDS drug trials in Thailand and Uganda}

To the editor-I would like to point out a factual error in your editorial "Uganda gives lessons in stemming the AIDS epidemic" in the September issue of Nature Medicine. The third paragraph states that the HIVNET 012 trial showed that a regimen of nevirapine "is almost twice as effective at reducing vertical transmission as the AZT regimen tested in Thailand last year...."

In fact, the HIVNET 012 trial compared nevirapine to a very different regimen of AZT. The regimen used in the Thai trial was $300 \mathrm{mg}$ twice daily beginning at 36 weeks of gestation and $300 \mathrm{mg}$ every 3 hours during labor ${ }^{1}$. The regimen used in the HIVNET trial in Uganda was $600 \mathrm{mg}$ at the onset of labor, $300 \mathrm{mg}$ every 3 hours during labor, and $4 \mathrm{mg} / \mathrm{kg}$ twice a day to children for 7 days $^{2}$. Thus, the Thai AZT regimen mainly targeted the mother and most likely acts to reduce maternal viral load, whereas the HIVNET 012 regimen mainly targeted the child and most likely acts as post-exposure prophylaxis. The nevirapine regimen used in the HIVNET 02 trial has not been compared with the AZT regimen used in the Thai trial in any studies.

As you know, many countries are now considering perinatal HIV intervention programs and might be misled or confused by this error.

\section{R.J. SIMONDS}

Chief, Epidemiology Section The HIV/AIDS Collaboration US Centers for Disease Control and Prevention Thailand Ministry of Public Health DMS 6 Bldg., MOPH, Tlvanon Road Nonthaburi 11000, Thailand

Email: rxs5@cdc.gov

1. Shaffer, N. et al. Short-course zidovudine for perinatal HIV-1 transmission in Bangkok, Thailand: a randomised controlled trial. Lancet 353, 773-780 (1999).

2. Guay, L.A. et al. Intrapartum and neonatal singledose nevirapine compared with zidovudine for prevention of mother-to-child transmission of HIV- 1 in Kampala, Uganda: HIVNET 012 randomised trial. Lancet 354, 795-802 (1999). 